\title{
ENCAPSULAMENTO ANAFÓRICO: DEFINIÇÃO E TIPOLOGIA
}

\section{Monclar Guimarães Lopes}

Resumo: Segundo Conte (2003, p. 178), o encapsulamento anafórico é "um recurso coesivo pelo qual um sintagma nominal funciona como uma paráfrase resumidora para uma porção precedente de texto". Patrocinamos, neste artigo, uma redefinição do fenômeno, na medida em que tanto há encapsulamentos de função pragmática - cujo escopo se encontra na enunciação - quanto outros que têm como núcleo um elemento mais gramaticalizado, e não um nome. Paralelamente, propomos um estudo tipológico dos encapsulamentos anafóricos por intermédio das categorias pragmáticas e semânticas da Gramática Discursivo-Funcional (HENGEVELD; MACKENZIE, 2008). Os dados coletados foram extraídos de 88 textos do gênero crítica de cinema, do jornal Folha de S.Paulo, entre os anos de 2008 e 2010.

Palavras-chave: Encapsulamento. Referenciação. Gramática discursivo-funcional.

\section{CONSIDERAÇÕES INICIAIS}

"N este artigo, tratamos do recurso coesivo conhecido como encapsulamento anafórico. Embora haja vários materiais que já abordem esse elemento textual, argumentamos que a principal contribuição de nosso estudo reside tanto em sua redefinição conceitual, quanto em sua classificação tipológica, ambas sob a ótica da Gramática Discursivo-Funcional (GDF) (HENGEVELD; MACKENZIE, 2008).

Em um primeiro momento, pode parecer equivocada a opção de se adotar uma gramática para a análise de um fenômeno textual. No entanto, tal teoria atende não somente ao estudo da fonologia e da morfossintaxe, como também à investigação do texto e do discurso, uma vez que seu modo de organização prevê 
a análise de todos os niveis de manifestação linguística. No que tange à análise da referência, por exemplo, a GDF (HENGEVELD; MACKENZIE, 2008, p. 5) propõe que se investiguem as anáforas sob seus diferentes níveis hierárquicos, como observamos a seguir:

1) Anáforas do nível interpessoal (ou pragmático):

A: - Saia daqui!

B: - Não fale comigo assim!

2) Anáforas do nível representacional (ou semântico):

A: - Há muitos semáforos nesta cidade!

B: - Eu não notei isso.

3) Anáforas do nível morfossintático:

A: - Eu comi lamb chops noite passada.

B: - É assim que vocês dizem "chuletas de cordeiro" em inglês?

4) Anáforas do nível fonológico:

A: - Eu comi /t fu'letasdekor'dero/ noite passada.

B: - Isso não deveria ser / Ju'letasdekor'dero/?

Nos dois primeiros exemplos, as anáforas destacadas podem ser consideradas encapsulamentos anafóricos, na medida em que fazem remissão a entidades de segunda e terceira ordens (LYONS, 1977), como estados-de-coisa, eventos, situações, processos, fatos, proposições e atos de enunciação, e não a sintagmas nominais presentes no cotexto prévio. Em (1), por exemplo, "assim" encapsula o tom e/ou a seleção vocabular utilizados na enunciação da frase; em (2), "isso" remete a todo o predicado.

Ao nosso estudo, o encapsulamento expresso no primeiro exemplo é particularmente relevante, uma vez que suas características permitem-nos redefinir esse fenômeno ao expandir sua manifestação para além do sintagma nominal e seu escopo para além do contexto precedente, características consideradas basilares por Conte em sua investigação ${ }^{1}$, a qual tem sido amplamente referenciada em pesquisas que tratam desse elemento de coesão.

O encapsulamento anafórico pode ser definido no seguinte modo: é um recurso coesivo pelo qual um sintagma nominal funciona como uma paráfrase resumidora para uma porção precedente do texto. Esta porção de texto (ou segmento) pode ser de extensão e complexidade variada - um parágrafo inteiro ou apenas uma sentença (CONTE, 2003, p. 178).

Na medida em que tomamos "assim", em (1), como um encapsulamento anafórico, é preciso considerar que a definição acima não lhe atende, visto que o elemento não se encontra em um sintagma nominal - mas adverbial -, nem remete a uma porção precedente de texto - e sim a informações contextuais, pertencentes à enunciação, e não ao enunciado. Por esse motivo, sugere-se uma reanálise conceitual a partir da observação do fenômeno em uso, articulado às categorias pragmáticas e semânticas da GDF. Em tal investigação, utilizaram-se como corpus 88 críticas de cinema, extraídas da Folha de S.Paulo.

1 Embora a obra referenciada seja de 2003, a autora vem estudando o encapsulamento anafórico desde 1980. 


\section{DEFINIÇÃo E CARACTERIZAÇÃo DO ENCAPSULAMENTO ANAFÓRICO}

Pautando-se em Schwarz (2000), Koch (2003) considera os encapsulamentos anafóricos nomes-núcleo inespecíficos que exigem realização lexical no cotexto, o que mostra sua concordância com Conte (2003). No entanto, uma vez que sua definição é mais abrangente e não restringe o recurso coesivo ao sintagma nominal e ao cotexto, adotamo-la em nosso estudo: o encapsulamento anafórico é "a sumarização de uma informação precedente, compartilhada pelos interlocutores” (KOCH, 2003, p. 94).

A despeito de compreendermos a relevância das pesquisas referenciadas anteriormente para o estudo do encapsulamento anafórico - até mesmo porque compartilham de pressupostos teóricos da análise da referência com os quais concordamos -, consideramos que seus estudos repousam num ponto de vista que se prende a critérios de ordem lexical e sintática. Isso equivale dizer que a preocupação na observação do fenômeno atende mais a aspectos de estruturação e organização contextual, o que configura uma visão simplificada para os processos de significação.

Tem-se como pressuposto que a linguagem é um trabalho que envolve atividades humanas, sócio-históricas, que se organizam por meio de textos, os quais não se caracterizam apenas por uma estrutura linguística, mas também por um funcionamento sociodiscursivo. Assim, a construção do texto, tanto em termos de produção quanto de intelecção, assume qualidades que ultrapassam a língua e o discurso, envolvendo processos sociocognitivos como memória discursiva, inferências, analogias e ação reflexiva dos sujeitos.

Nesse sentido, este estudo propõe uma ampliação do fenômeno com base na GDF, sugerindo que a âncora de um encapsulamento não se encontra apenas em uma predicação ou segmento de texto, como também no contexto discursivo-pragmático, conforme se pôde perceber no exemplo (1) e observar no exemplo (5), a seguir, em que o encapsulamento destacado remete ao contexto, mais especificamente a uma atitude subjetiva do locutor, e não ao conteúdo anteriormente expresso.

5) A: - Aquela mulher me paga!

B: - Essa raiva ainda vai deixá-la doente.

Tanto em (1) quanto em (5), que defendemos se tratarem de encapsulamentos de natureza contextual, temos uma sequência dialogal, normalmente presente em interações face a face, em que a remissão a anáforas que tenham como escopo a enunciação manifesta-se com mais frequência. Nos textos de modalidade escrita, em contrapartida, a tendência é remeter-se menos ao contexto, sobretudo quando o destinatário é um interlocutor genérico, plural. Nesse caso, tendo menos controle sobre o processo de compreensão daquilo que produz - na medida em que o produtor e destinatários estão fisicamente distantes -, o produtor procura garantir que os sentidos que pretende transmitir estejam materializados no próprio texto. Inclusive, talvez esse seja um dos motivos por que os estudos que tratam do encapsulamento anafórico o reconheçam apenas como um elemento de remissão a informações presentes no cotexto.

Quanto à representação do encapsulamento anafórico por um elemento de núcleo gramatical, como ocorre no exemplo (1) - "assim" -, é importante frisar 
que, neste caso, trata-se de um diferente tipo de encapsulamento. Os encapsulamentos anafóricos representados por sintagmas nominais dão à expressão/ predicação encapsulada o estatuto de referente, na medida em que o transformam em tópico, objeto-de-discurso. Entretanto, a despeito de elementos gramaticais - como o expresso em (5) - não transformarem a informação precedente em tópico discursivo, eles encapsulam informação precedente e promovem a progressão temática do texto, muito embora através de outra categoria morfossintática.

Não obstante a discordância quanto ao escopo e à restrição morfológica do núcleo do encapsulamento anafórico, sustentamos as demais descrições apresentadas por Koch $(2003,2005)$, Conte (2003) e Neves (2006) quanto à caracterização e ao funcionamento desse recurso coesivo, apresentados a seguir.

\section{ROTULAÇÃO, NOMINALIZAÇÃO E PRONOMINALIZAÇÃo}

Conte (2003), Koch (2003) e Neves (2006) apontam uma clara tendência pela representação do encapsulamento anafórico por meio de sintagma nominal de núcleo substantivo, subtipo nomeado rotulação por Francis (2003). Essas autoras concordam que a rotulação seja um encapsulamento de grande valor para a progressão argumentativa do texto, uma vez que permite a categorização através de nomes axiológicos, que revelam as intenções persuasivas do falante, tal como se pode observar no exemplo a seguir, em que o substantivo "subversão" representa uma avaliação do segmento de texto destacado.

6) [...l Um pais inexistente precisa de uma receita de salada de ovos para ser reconhecido, os olhares do herói são transformados em taras sexuais e suas agressões verbais são absurdos xingamentos nacionalistas.

Subversão no sentido literal, a versão sub, que vem de baixo e atinge a bunda dos donos das verdades institucionalizadas (Crítica de Cinema, "DVDs retomam Allen Pastelão”. Folha de S.Paulo, 11 jan. 2009).

Outra representação bastante frequente do encapsulamento anafórico é a nominalização. Caracteriza-se pela remissão a um sintagma verbal previamente citado no texto, não em uma predicação ou porção maior de texto. Nesse caso, o encapsulador é um lexema-núcleo resultante de uma transformação verbo-nominal, ou seja, derivado morfologicamente do verbo presente no contexto, como se vê no exemplo a seguir, em que o vocábulo "sonho" foi transformado em objeto-de-discurso com base no referente construído pela locução verbal "foi sonhada".

7) [...] No passado, a liberdade tanto podia ser essa, liberal, que conhecemos hoje (que parece, a que está em crise financeira), como a que foi sonhada pela humanidade a partir do desenvolvimento da indústria, sonho segundo o qual as máquinas nos libertariam e trabalhariam por nós. [...] (Crítica de Cinema - "Em 'Bourne', Estado suprime liberdade”. Folha de S.Paulo, 5 out. 2008).

Por fim, há ainda encapsulamentos anafóricos representados por pronominalizações - em sintagmas em que o pronome ou o advérbio pronominal seja o elemento nuclear. Nesses casos, o encapsulamento apresenta-se como um ele- 
mento não axiológico, que dá estatuto referencial (transforma em tema) a uma entidade de segunda ou terceira ordem (não individualizadas), como se vê a seguir.

8) [...] Regada a violência e a temas polêmicos, "Shield" tem pouco ou nada a ver com a maioria das séries atuais. Ela quer entreter, sim, mas faz isso percorrendo algumas das vielas mais escuras e fétidas da alma humana (Crítica de Cinema - "Com Glenn Close, série vê lado podre da vida". Folha de S.Paulo, 10 ago. 2008).

\section{MOTIVAÇÃo PARA UM ESTUdo TIPOLÓGICO DOS ENCAPSULAMENTOS}

No que tange à literatura vigente, vários autores têm-se debruçado sobre o fenômeno da referenciação feito por meio de encapsulamentos. Uns por uma perspectiva sistêmico-funcional (FRANCIS, 2003), alguns por uma perspectiva textual (CONTE, 2003), e outros por uma perspectiva sociocognitiva (MONDADA; DUBOIS, 2003; APOTHÉLOZ; REICHLER-BÉGUELIN, 2003).

Embora tais linhas de estudo da referenciação sejam variadas, esta investigação aproxima-se da perspectiva de Francis (2003), uma vez que a GDF também tem como base as metafunções linguísticas elaboradas pela Linguística Sistêmico-Funcional (HALLIDAY, 1985). Contudo, trata-se, na verdade, de uma perspectiva discursivo-funcional da referência, considerando-se sua associação ao modelo da GDF.

Não obstante, tal perspectiva não se afasta de uma concepção sociocognitiva da linguagem. As duas teorias compreendem a importância da práxis e compartilham a ideia de que é por meio dela que se constrói o discurso. Portanto, a perspectiva sociocognitiva da referência e a discursivo-funcional são linhas complementares. A diferença tênue entre as duas é que a primeira se preocupa com o processo em si, isto é, em como se dá a construção dos objetos-de-discurso, e a segunda, em como tais processos discursivos manifestam-se na cadeia linguística.

Francis (2003), fazendo uso das metafunções textual - que diz respeito à criação de textos adequados às necessidades comunicacionais - e ideacional relacionada à interpretação e expressão de nossa experiência acerca dos processos do mundo exterior e dos processos mentais e abstratos de todos os tipos - da Linguística Sistêmico-Funcional (HALLIDAY, 1985), propôs uma classificação para as rotulações. Por essa perspectiva, chegou à conclusão de que as rotulações podem fazer remissão a um conteúdo expresso no contexto ou a um ato de linguagem. Ao primeiro deu o nome de rótulos de conteúdo e, ao último, de rótulos metalinguísticos, estando este subdividido nos seguintes grupos: ilocucionários, de atividades linguageiras, de processo mental e de textos.

Uma vez que a GDF elabora seus niveis de análise a partir das metafunções da Linguística Sistêmico-Funcional, representando, de certo modo, uma expansão do trabalho de Halliday, resolvemos empregar uma metodologia semelhante à utilizada por Francis (2003). No entanto, em vez de investigarmos apenas as rotulações, analisamos os diferentes tipos de encapsulamento anafórico, por recurso às categorias pragmáticas e semânticas dos níveis interpessoal e representacional da GDF. 


\section{A GRAMÁTICA DISCURSIVO-FUNCIONAL E OS NÍVEIS INTERPESSOAL E REPRESENTACIONAL}

A GDF constitui uma abordagem funcionalista recente para a análise linguística. Elaborada por Hengeveld e Mackenzie (2008), tal teoria se diferencia por conceber uma organização top-down da gramática, isto é, ela parte da cadeia mais alta da hierarquia linguística, a intenção do falante, e faz sua análise até o componente de saída, a articulação. Começou a ser esboçada em 1997 por Kees Hengeveld em um texto intitulado Cohesion in functional grammar, no qual Hengeveld propõe um modelo discursivo com base nas ideias apresentadas no último capítulo de Dik (1989), dedicado ao discurso e às propriedades pragmáticas e psicológicas que um modelo de base discursiva deve apresentar. Depois de algumas versões da GDF, publicadas em diferentes revistas e livros, Hengeveld e Mackenzie lançaram, no segundo semestre de 2008, o livro Functional discourse-grammar: a typologically-based theory of language structure, que traz uma versão completa e atualizada da GDF.

Para Hengeveld e Mackenzie (2008, p. 2), a GDF pode ser definida mais concisamente como uma teoria que procura entender como as unidades linguísticas são estruturadas em termos do mundo que elas descrevem e das intenções comunicativas com que elas são produzidas. Assumindo o ato discursivo como unidade de análise, o discurso passa a ser, na GDF, o "suporte" das unidades linguísticas de niveis mais baixos. Enquanto a Gramática Funcional de Dik começa com a seleção de itens lexicais, para, em seguida, expandir gradualmente a estrutura subjacente da oração, a GDF inicia-se com a formulação da intenção do falante, finalizando com a realização da expressão linguística.

De modo geral, a organização linguística da GDF dá-se por meio de quatro niveis, a saber: o interpessoal (ou pragmático), o representacional (ou semântico), o morfossintático e o fonológico. À nossa pesquisa, interessam apenas os dois primeiros.

\section{O nível interpessoal (ou pragmático)}

O nivel interpessoal (NI), como o nome sugere, equivale ao que Halliday (1985) nomeou de função interpessoal da língua. Esse é o nivel que lida com os aspectos formais de uma unidade linguística que reflete seu papel na interação dos participantes, cada qual com um propósito comunicativo em mente. O NI implica a ideia de que cada falante emprega uma estratégia de modo mais ou menos consciente para atingir seus objetivos comunicativos. Em alguns casos, esse propósito pode ser bastante explícito, como em uma entrevista de emprego; em outros, ele pode ser meramente elaborado para estabelecer e manter relações sociais.

Nesse sentido, os aspectos discursivos pertencentes a esse nivel são aqueles que dão conta das funções retóricas e pragmáticas da lingua. Por função retórica, entende-se a forma como os componentes discursivos são ordenados para que o falante atinja seus objetivos comunicativos e também as propriedades formais dos enunciados que influenciam o destinatário a aceitar os propósitos comunicativos de seu interlocutor. Por função pragmática, entende-se, aqui, a forma como os interlocutores moldam suas mensagens com base nas expectativas atuais do estado mental do destinatário.

O objetivo de tratar tais funções é o de explicitar que as decisões comunicativas do falante não são tomadas a partir da gramática, mas, sim, de um com- 
ponente conceitual. Na verdade, é esse componente que contém as intenções comunicativas do falante e as estratégias que ele deseja usar para obtê-las.

Se, por exemplo, numa dada situação, o ouvinte B está próximo à janela de sua sala de estar e escuta do falante A o enunciado "Está frio aqui dentro!", é muito provável que B interprete tal enunciado como "Feche a janela", e não apenas como um comentário. No entanto, se A e B estivessem em um local em que ambos não tivessem liberdade de executar o ato de fechar a janela, o mesmo enunciado, provavelmente, seria interpretado somente como um comentário. Tais exemplos mostram que a análise linguística, em termos de ilocução, não pode ser feita sem se levar em conta aspectos pragmáticos e retóricos. Diz-se também retóricos porque a opção entre "Está frio aqui dentro" e "Feche a janela" não é neutra. Há, por trás de tais enunciados, princípios de polidez e papéis sociais que precisam ser evidenciados na análise linguística.

\section{O nível representacional (ou semântico)}

O nivel representacional (NR) trabalha com as funções ideacional e textual, e com a manifestação de conteúdos que estejam ligados à experiência que o falante possui do mundo concreto, real ou de seu universo subjetivo, interior. Segundo Hengeveld e Mackenzie (2008, p. 130), dado que as unidades do NR são caracterizadas pelo fato de que elas designam, as diferenças entre as unidades desse nível podem ser estabelecidas em termos de quatro categorias ontológicas básicas, ou melhor, semânticas, a saber:

a) Entidades de primeira ordem: indivíduos. Eles podem ser localizados no espaço e podem ser avaliados em termos existenciais.

b) Entidades de segunda ordem: estados-de-coisas. Podem ser localizados no espaço e no tempo e podem ser avaliados em relação a sua realidade.

c) Entidades de terceira ordem: conteúdos proposicionais. São construções mentais que não podem ser localizadas nem no espaço nem no tempo, mas que podem ser avaliadas em termos de verdade.

d) Entidades de ordem zero: propriedades. Não podem ser caracterizadas por parâmetros de espaço e tempo e não têm existência independente. Só podem ser avaliadas em termos de sua aplicabilidade a outros tipos de entidade ou à situação a qual descreve.

Para exemplificar as entidades de ordem zero, Hengeveld e Mackenzie (2008) recorrem aos exemplos: "verde", uma propriedade de entidades de primeira ordem; "recente", de segunda ordem; "inegável", de terceira ordem.

Às categorias ontológicas básicas, acrescem-se as categorias semânticas secundárias, com suas unidades de lugar, tempo, modo, razão e quantidade. Ainda no NR, acrescenta-se uma última unidade semântica que trabalha com a metafunção textual: a língua reflexiva.

\section{ENCAPSULAMENTOS PRAGMÁTICOS}

Temos um encapsulamento pragmático quando o encapsulador faz remissão a um ato ilocucionário, que pertence ao nível pragmático, isto é, a enunciação. 
Vale ressaltar que, diferentemente de Searle (1972), para quem há cinco tipos de ilocuções, para Hengeveld e Mackenzie (2008, p. 71) há 12 diferentes tipos, a saber:

- Declarativa (DECL): o falante informa o ouvinte do conteúdo proposicional evocado.

- Interrogativa (INT): o falante requisita ao ouvinte responder ao conteúdo proposicional evocado.

- Imperativa (IMPER): o falante delega ao ouvinte a responsabilidade de fazer uma ação evocada.

- Proibitiva (PROH): o falante proíbe o ouvinte de fazer uma ação evocada.

- Optativa (OPT): o falante indica ao ouvinte seu desejo que a situação positiva evocada pelo conteúdo comunicado ocorra.

- Imprecativa (IMPR): o falante indica ao ouvinte seu desejo que a situação positiva evocada pelo conteúdo comunicado ocorra.

- Exortativo (HORT): o falante encoraja o ouvinte ou a si mesmo a fazer uma ação evocada no conteúdo comunicado.

- Não-exortativo (DISHORT): o falante desencoraja o ouvinte ou a si mesmo a fazer uma ação evocada no conteúdo comunicado.

- Admonitiva (ADMON): o falante adverte o ouvinte a realizar a situação evocada pelo conteúdo comunicado.

- Comissiva (COMM): o falante promete a si mesmo a realizar uma situação futura evocada pelo conteúdo comunicado.

- Suplicativa (SUPPL): o falante pede permissão ao ouvinte para realizar a situação evocada pelo conteúdo comunicado.

- Mirativa (MIR): o falante expressa sua surpresa sobre o conteúdo comunicado evocado (HENGEVELD; MACKENZIE, 2008, p. 71).

Nesse sentido, quando retomamos o exemplo expresso em (1), "Não fale comigo assim!", observamos que a forma "assim" encapsula uma ilocução não-exortativa, deixando claro que desaprova que seu interlocutor continue lhe dirigindo a palavra sem a devida educação. Nesse caso, além de o encapsulador representar, nessa sentença, uma ilocução exortativa, sua remissão é mais contextual que contextual, na medida em que poderíamos admitir que a mesma mensagem, se dita em tom educado ou com outra seleção vocabular, seria bem recebida.

Não obstante, há também encapsulamentos pragmáticos em que encontramos remissão à superfície do texto. Contudo, o que nos leva a considerá-los do nivel pragmático é a preponderância da remissão ao ato ilocucionário, como vemos, no exemplo a seguir, no sintagma "essa opção", que atribui à predicação sublinhada uma ilocução optativa:

9) Todo mundo diz que o segredo para pagar mais barato é pesquisar, mas existem situações em que você não tem essa opção. ${ }^{2}$ 


\section{ENCAPSULAMENTOS SEMÂNTICOS}

Os encapsulamentos semânticos dividem-se em três grupos: semânticos básicos (que se subdividem em quatro tipos: conteúdos proposicionais, episódios, estados-de-coisas e propriedades); semânticos secundários, que se referem a entidades de segunda, terceira e ordem zero, de metafunção ideacional (que se subdividem em três tipos: modo, razão e quantidade); e metalinguísticos, de metafunção textual.

\section{Encapsuladores de conteúdo proposicional}

São aqueles que capturam (ou inferem) seja a própria atitude proposicional expressa (certeza, dúvida, descrença), seja a sua origem (conhecimento comum partilhado, evidência sensorial, inferência) em uma predicação ou segmento maior de texto.

10) [...] Existe, por um lado, a perseguição: ela em si é interessante e tensa. Mas existe, sobretudo, a dúvida: teria sido ela, de fato, raptada? Entramos num terreno muito frequentado por Brooks: o da liberdade feminina [...] (Crítica de Cinema - "Faroeste aborda liberdade feminina". Folha de S. Paulo, 2 nov. 2008).

11) [...] A consciência do corpo é um dado expressivo no cinema de Paul Verhoeven. Consciência que vem da própria situação na qual estão os personagens, geralmente esmagados pelo sistema. É uma constatação, então, que ultrapassa o fisico para chegar a algo além: o próprio mundo. É assim com o corpo biomecânico do policial que é utilizado por uma megacorporação em "Roboco" [...] (Crítica de Cinema - "Verhoeven retrata faroeste amoral". Folha de S.Paulo, 3 ago. 2008).

Em (10), o encapsulador prospectivo “dúvida” faz remissão à atitude proposicional expressa pela predicação "teria sido ela, de fato, raptada?", em que o emprego verbal do futuro do pretérito sugere a própria dúvida. Já em (11), o encapsulador retrospectivo "uma constatação" faz remissão à atitude proposicional do segmento sublinhado e tem o estatuto de inferivel, pois não há marcas, no trecho encapsulado, de que se trata de uma certeza percebida, muito embora o segmento seja assertivo.

\section{Encapsuladores de episódio}

São aqueles que fazem remissão a um episódio, isto é, a uma sequência coerente de texto, em que há unidade ou continuação de tempo, lugar e participantes.

12) [...] Exemplo mais evidente, mas não único: a cena final de "Otelo", em que Tony estrangula não só Desdêmona, como, ao mesmo tempo, Brita (Signe Hasso), sua ex-mulher - o público do teatro, e nós também, ficamos em suspense, sem saber em que nível estamos, se no da vida ou no da representação.

Embora esses momentos sejam intensos, ofato é que, até a cena de assassinato (sim, acontece um no filme), "Fatalidade" deixa a impressão de que 
sua maior vocação é para uma magnífica "comédia do recasamento", dessas que Garson Kanin escreveu com maestria (às vezes na companhia de Gordon) e que Cukor dirigiu com a sensibilidade que se conhece [...] (Crítica de Cinema - "Filme de Cukor aproxima a vida e o palco". Folha de S.Paulo, 23 nov. 2008).

O exemplo (12) encapsula o episódio expresso pelo segmento destacado, transformando-o em tópico discursivo. Esse tipo de encapsulador mostrou-se, em nossa pesquisa, bastante frequente nos parágrafos em que se marca a transição narração-argumentação. Acredita-se que tal recurso de remissão seja favorável ao próprio gênero discursivo em análise, uma vez que um enredo ou parte de um enredo torna-se produto a ser avaliado.

Existem nomes típicos que costumam representar núcleos de encapsuladores de episódio, tais como: acontecimento, aventura, cena, conto, encenação, enredo, episódio, história, incidente, momento, narração, narrativa, ocorrido e relato. No entanto, além dos nomes, encontram-se elementos de núcleos adverbiais que, embora representados por advérbios de lugar ou de tempo, capturam os estados-de-coisas, o tempo, o lugar e os participantes expressos no episódio, como exemplificado a seguir:

13) Em "O Menino Peixe", ela faz a garota de classe média alta Lala, enamorada da doméstica paraguaia La Guayi, que trabalha em sua casa em Buenos Aires. Elas têm planos de morar juntas perto de um lago no Paraguai, mas um assassinato as separa e põe Lala numa viagem de descoberta ao país vizinho.

É aqui que surge o momento fantástico, quando Lala encontra um dos segredos de sua amada, numa cena subaquática realizada com efeitos especiais. A diretora admite que, na mistura de gêneros, foi complicado deixar a sala de edição [...] (Crítica de Cinema - "Argentina narra fantasia de casal gay”. Folha de S.Paulo, 1 nov. 2009).

14) Era, porém, previsível que o formato logo cansaria. E, na temporada anterior, uma nova aposta foi feita. Copiando um pouco o modelo de "Six Feet Under" (Alan Ball), os episódios continuaram a exibir, no começo, um caso desesperador que logo iria parar num dos leitos do Princeton-Plainsboro Hospital, em Nova Jersey. Só que o enigma clínico passou a causar um impacto mais significativo nos relacionamentos entre os personagens.

A série, então, passou a evoluir como uma novela, trazendo mais continuidade entre capitulos e com os dramas individuais ganhando consistência [...] (Crítica de Cinema - “House' luta para não virar 'one-man-show”. Folha de S.Paulo, 28 set. 2008).

Em (13) e (14), "aqui" e "então" encapsulam as sequências narrativas destacadas. Embora sejam prototipicamente circunstâncias de lugar e de tempo, nos casos em análise, remetem-se a todo episódio.

\section{Encapsuladores de estado-de-coisas}

São aqueles que fazem remissão a um estado-de-coisas previamente citado no texto. Por estado-de-coisas entendem-se as entidades que podem ser locali- 
zadas no tempo relativo e avaliadas em termos de sua realidade. Estão diretamente relacionados aos processos, isto é, aos "elementos responsáveis por codificar ações, eventos, estabelecer relações, exprimir ideias e sentimentos, construir o dizer e o existir" (CUNHA; SOUZA, 2007, p. 55). Com frequência, são encapsulados por uma nominalização, muito embora nem sempre esse processo seja feito por uma palavra cognata, tal como ocorre no exemplo (15), em que "essa convocação" representa uma nominalização que remete ao segmento que tem como base a forma verbal "conclamara".

15) [...] Em 1972, o Brasil, no momento mais duro do regime militar, comemorava de maneira ufanista o Sesquicentenário da Independência. Pouco antes, o então ministro da Educação, Jarbas Passarinho, conclamara os cineastas brasileiros a fazer filmes sobre temas históricos. "Os inconfindentes" é, por um lado, a resposta marota de Joaquim Pedro de Andrade a essa convocação (Crítica de Cinema - "Cineasta revisita inconfidência com ironia". Folha de S.Paulo, 7 set. 2008).

No entanto, é importante frisar que nem sempre esses encapsuladores são nominalizações, como observamos a seguir, no exemplo (16), no encapsulador "essa última circunstância", que faz remissão ao segmento "ama e é amada". Paralelamente, são bastante frequentes os casos em que há remissão a estado-de-coisas por meio de pronome demonstrativo, de função endofórica, como vemos em (17). Acredita-se que tal aspecto se deve ao fato de que alguns estados-de-coisas representam, na maioria das vezes, o foco comunicativo e, por serem a informação mais saliente na memória do falante, este recorre apenas ao pronome demonstrativo, transformando o estado-de-coisas em tópico.

16) [...] Como não ganhou, temos então um mero "filme de doença", no caso o mal de Alzheimer. O roteiro cerca todas as circunstâncias que tornem a situação explícita, no que tem de particular ou de geral. Fiona não é uma mulher especialmente idosa (de modo que não devemos estabelecer uma relação obrigatória entre idade e doença). É culta, casada há muitos anos, ama e é amada.

Essa última circunstância é essencial: "Longe Dela" precisa ser uma "love story" para ser engolida pelo espectador [...] (Crítica de Cinema - "'Longe Dela' cativa pela sensibilidade”. Folha de S.Paulo, 12 out. 2008).

17) [...] Desde então, "Curb Your Enthusiasm" (HBO) inseriu em sua trama o que seriam os bastidores do elenco original de "Seinfeld" se reunindo para fazer mais um episódio da série, que foi de 1990 a 1998 e marcou um dos últimos momentos de criatividade de um formato - a sitcom, com três câmeras e riso da plateia - inventado nos anos 50 e que dura até hoje. Sendo Larry David o autor e ator de "Curb", a reunião não será de verdade. É o que a tribo de espectadores vem descobrindo a cada semana. Por exemplo, nos quatro episódios exibidos até agora, os quatro atores de "Seinfeld" só aparecem em um - nos outros, são só mencionados, aparecem em pequenas cenas ou nem isso [...] (Crítica de Cinema - "Elenco de 'Seinfeld' está de volta (mas não muito)”. Folha de S.Paulo, 18 nov. 2009). 


\section{Encapsuladores atribuidores de propriedade}

Tais encapsuladores mostram-se bem diferentes das categorias até aqui apresentadas. Na verdade, eles não encapsulam uma propriedade, mas um estado-de-coisas ou, até mesmo, todo um episódio, atribuindo-lhe uma propriedade. Muitas vezes, a porção de texto a que esse encapsulador remete-se não é claramente delimitável no texto, como podemos observar no exemplo (18), em que o encapsulador "essa queda" não aponta um segmento específico do texto.

18) [...] Um pouco depois, "Bananas", de 1971, é ainda mais farsesco. Após se apaixonar por Nancy (Louise Lasser), o solitário Fielding Mellish (Woody Allen) vai parar na típica republiqueta latino-americana de San Marcos.

De sequestrado pelos rebeldes acaba se tornando presidente. (Ah, como eu gostaria de assistir ao lado do ilustre chefe de nosso país para acompanhar seus sábios comentários futebolísticos sobre presidentes que têm seu poder mensurado pelo que pesam em estrume!) É só um devaneio, como os tantos de Allen, que insere filmetes paralelos - que poderiam ser campeões no YouTube -, como o sonho do judeu crucificado disputando uma vaga de estacionamento e o comercial do cigarro Novo Testamento. Não estão ali à toa, completam as personagens e nos situam na época por meio da provocação. Woody Allen é anárquico, não se compromete com nenhum tipo de poder. Zomba dele com uma barba mais falsa que promessa de campanha eleitoral. Está nos dizendo que só acreditamos no que aceitamos acreditar. Nessa fase paleolítica, Allen já aponta seu estilo, que vai além de sua figura caricata de baixinho desajeitado com óculos de aros grossos. Casais em diálogos frenéticos apontam o que virá depois, com noivos neuróticos $e$ pessoas curiosas para saber tudo sobre sexo. Divãs de analistas, pais e mães superprotetores não escapam de seu olhar obliquo. Comediantes têm essa queda por inverter o olhar [...] (Crítica de Cinema - "DVDs retomam Allen pastelão". Folha de S.Paulo, 11 jan. 2009).

Nesse exemplo, a referência "essa queda" é apenas inferivel, podendo representar a postura anárquica de Allen, que sempre questiona os sistemas e as crenças. Acredita-se que encapsuladores como esse tenham, sobretudo, certa dependência contextual, e não somente cotextual. Aproximam-se do que Gary-Prieur e Noailly (2003) intitularam demonstrativos insólitos, uma categoria em que o destinatário não consegue identificar ou inferir o "referente". Por esse motivo, defende-se que tais encapsulamentos só podem ser compreendidos por meio de uma análise discursiva mais ampla, e não apenas através de recursos endofóricos.

No entanto, o estatuto encapsulador atribuidor de propriedade nem sempre é inferivel. Como se afirmou anteriormente, embora haja remissão a um estado-de-coisas ou a um episódio, tal processo não ocorre de forma direta, pois se remete sem encapsular o segmento. Nesse caso, a categoria que se transforma em tópico é a propriedade, e não a predicação ou segmento de texto. Pode-se observar tal característica no exemplo (19), no encapsulador "essa naturalidade para o 'diferente":

19) [...] Mistura de romance, aventura e fantasia, "O Menino Peixe" conta a saga de duas jovens que se envolvem em roubos e assassinatos, numa série de eventos tão burlescos que, no final das contas, o menor de seus problemas é serem namoradas e de classes sociais distintas. 
Essa naturalidade para o "diferente" já estava no primeiro longa da diretora argentina [...] (Crítica de Cinema - "Argentina narra fantasia de casal gay”. Folha de S.Paulo, $1^{\circ}$ nov. 2009).

\section{Encapsuladores de modo}

Podem ser de dois tipos: 1. aqueles que fazem remissão a uma circunstância de modo expressa no texto, encapsulando não apenas o modo, como também o estado-de-coisas. O que o difere de um encapsulador de estado-de-coisas é o fato de ser representado por um nome ou advérbio que indica a função de modo, deixando-se, assim, a circunstância em evidência; 2. aqueles que, embora não haja circunstâncias de modo nos conteúdos a que se remetem, encapsulam um ou mais estados-de-coisas e atribuem-lhe ad hoc tal circunstância. Seguem os exemplos:

20) [...] Um dos conceitos básicos desta teoria é que nenhum objeto físico deste universo pode viajar a uma velocidade maior que a velocidade da luz, ou seja, nenhum objeto pode viajar a uma velocidade maior que $300.000 \mathrm{~km} / \mathrm{s}$ (aproximadamente). Mas, sem dúvida, o conceito mais importante da Teoria da Relatividade é a famosa afirmação da "equivalência entre massa e energia", expressa através da equação $E=m c^{2}$. Essa fascinante fórmula nos diz que, devida a relatividade, a massa de um corpo aumenta quanto mais rapidamente este se mover. Desse modo, o corpo ganha energia cinética (a energia de movimento), que é diretamente proporcional a massa do corpo e ao quadrado de sua velocidade [...] ("Velocidade de dobra").

21) Malu Mader toma banho, sai do chuveiro, coloca uma calcinha preta, bota de couro, coldre nas costas e dá um beijo no bebê. Assim dá início a mais um dia. Mas não da atriz carioca de 43 anos, e sim de sua personagem Diana Maciek, de "A Justiceira", que tem lançamento neste mês em DVD [...] (Crítica de cinema - "Malu Mader ataca como matadora". Folha de S.Paulo, 7 jun. 2009).

Em (21), "desse modo" encapsula "mover mais rapidamente", em que há explícita uma circunstância de modo. Já em (22), não há circunstância de modo expressa no trecho a que "assim" se refere. Nesse caso, infere-se que tal circunstância depende mais do discurso, no momento em que a designação é feita.

\section{Encapsuladores de razão (ou causa)}

Ocorrem da mesma forma que os encapsuladores de modo, isto é, podem basear-se em âncoras textuais ou não.

22) [...] O procurador de Udine, Antônio Biancardi, autorizou nesta quarta-feira o enterro de Eluana Englaro, 38, a italiana em coma há 17 anos e que a família ajudou a morrer nesta segunda-feira (9) depois da suspensão da alimentação e hidratação.

Ela morreu de sede após 17 anos. A autorização da Justiça coincide com a opinião do procurador-geral da Corte de Apelação de Trieste, Beniamino

\footnotetext{
3 Disponível em: http://inpu.sites.uol.com.br/veldobra.htm. Acesso em: 15 jan. 2010.
} 
Deidda, que afirmou nesta quarta-feira que a causa da morte da jovem é compativel com o protocolo médico [...] (Site JusBrasil - "Justiça autoriza enterro de Eluana; Italiana Morreu de Sede"4).

23) [...] Existe uma, e apenas uma, razão para o lançamento de "Uma Vida sem Regras" no Brasil: Robert Pattinson estar no papel principal [...] (Crítica de Cinema - “'Gata em Teto de Zinco Quente' é próximo filme de coleção”. Folha de S.Paulo, 9 abr. 2009).

Em (23), “a causa” faz remissão à locução adverbial "de sede" e ao estado-de-coisas expresso, isto é, "morrer de sede". Já em (24), "uma razão" encapsula o segmento destacado como motivo para o lançamento de um filme no Brasil.

\section{Encapsuladores de quantidade}

Quantidade é uma categoria que se associa não apenas a sintagmas verbais, como também a indivíduos, isto é, referentes. Por conseguinte, uma vez que o encapsulamento exige, pelo menos, uma entidade de segunda ordem, terceira ordem ou ordem zero a que se faça remissão, só haverá encapsulamento de quantidade se houver expressão adverbial no predicado que possa ser encapsulada por nome que expresse essa ideia (por exemplo: número, quantidade, frequência etc.); ou se houver elementos gramaticais que façam remissão a um ou mais estados-de-coisas, a cuja função possa ser atribuída ideia de quantidade.

24) Você sabe que eu viajo várias vezes ao ano e ainda não se acostumou com tal frequência?

No exemplo (24), "tal frequência" faz remissão à predicação "eu viajo várias vezes ao ano", elencando a frequência como núcleo encapsulador, daí a sua classificação.

25) [...] Quando o filme foi lancado, em setembro de 1968, Newman tinha 33 anos, e Taylor, 26. Apesar de jovens, os dois enfrentaram diálogos densos e cortantes do filme com impressionante maturidade. "Nem a vigorosa direção de Richard Brooks nem o provocativo texto de Tennessee Williams apagam o que 'Gata em Teto de Zinco Quente' tem de mais memorável: o duelo entre Elizabeth Taylor e Paul Newman", afirma o crítico da Folha Cássio Starling Carlos, no livro que acompanha o DVD.

O livro traz, ainda, biografias do diretor, Richard Brooks, do dramaturgo Tennessee Williams e um texto sobre a censura imposta à peça e ao roteiro, entre outras informações e curiosidades (Crítica de Cinema - "Gata em Teto de Zinco Quente’ é próximo filme de coleção”. Folha de S.Paulo, 9 abr. 2009).

26) [...] O mistério, a inquietação, a loucura da guerra e a aventura lisérgica foram substituidos pela contemplação enfadonha. Músicas adicionais "inéditas" de Carmine Coppola, pai do diretor, não faziam falta no original. Além disso, a temerária remarcação de luz "plastificou" a fotografia de Vittorio Storaro [...] (Crítica de Cinema - "Obra mítica de Coppola é melhor na versão “curta”. Folha de S.Paulo, 11 out. 2009).

4 Disponível em: https://www.jusbrasil.com.br/noticias/775172/justica-autoriza-enterro-de-eluana-italianamorreu-de-sede. Acesso em: 3 maio 2019. 
Em (26) e (27), "ainda" e "além disso" encapsulam os respectivos segmentos prévios de texto e atribuem-lhes a ideia de quantidade (além do que foi citado).

\section{Encapsuladores metalinguísticos}

Ao contrário das outras categorias semânticas, esses pertencem à metafunção textual da língua e servem para falar do evento comunicativo em si. Caracterizam, como aponta Jakobson (1971 apud HENGEVELD; MACKENZIE, 2008, p. 175), a mensagem sobre o próprio código.

São representados por duas categorias: 1 . nomes que se referem a alguns tipos de atividade linguageira ou aos seus resultados, como debate, definição, descrição, explicação, exposição, mensagem, pergunta etc.; e 2. nomes que se referem à estrutura textual formal do discurso, como citação, excerto, página, parágrafo, passagem etc.

27) [...] Escutamos os argumentos de ambos os lados, mas sempre mantemos a convicção de que o essencial escapa. Ou seja, nunca nos é dito por que esse homem deseja se suicidar. Correu, na época do lançamento do filme, que esse homem seria homossexual, o que configuraria um duplo crime diante da lei islâmica (o primeiro sendo o suicídio).

A explicação está longe de ser convincente, ao menos à luz do que se vê no filme: Badii surge apenas como um sujeito com um carro em busca de alguém que preste um serviço [...] (Crítica de Cinema - "Essência escapa em 'O Gosto da Cereja”. Folha de S.Paulo, 16 nov. 2008).

28) [...] Uma frase entrou para o folclore americano: "Se o presidente faz, então, não é ilegal”. A encenação do pingue-pongue entre Nixon e Frost, com seus bastidores, já havia feito sucesso no teatro. O autor, Peter Morgan ("A Rainha"), assina também o roteiro do longa, que emplacou cinco indicações ao Globo de Ouro: filme, diretor, roteiro, ator dramático para Frank Langella (que vive Nixon) e trilha [...] (Crítica de Cinema - "Filme mostra 'julgamento' de Nixon". Folha de S.Paulo, 4 jan. 2009).

Nos exemplos citados, "explicação" e "uma frase" nomeiam atividades linguageiras ao fazer remissão aos trechos destacados. A seguir, "trecho" nomeia uma parte formal do discurso.

29) [...] "Na segunda de manhã, o garoto aniversariante estava indo para a escola com outro garoto. Um saco de batata frita passava de uma mão para a outra e o aniversariante tentava descobrir o que seu amigo ia the dar de presente naquela tarde. Distraido, o aniversariante pisou em falso no meiofio, num cruzamento, e foi imediatamente atropelado por um carro." Extraído do conto "Uma Coisinha Boa", o trecho acima ilustra o estilo seco de observação do cotidiano que caracterizava o norte-americano Raymond Carver (1939-1988) [...] (Crítica de Cinema - "Filme-mosaico com dramas cotidianos é ponto alto na obra de Robert Altman”. Folha de S.Paulo, 15 nov. 2009). 


\section{Considerações Finais}

Neste estudo, realizou-se uma análise qualitativa da categorização dos encapsulamentos anafóricos a partir do exame de textos de crítica de cinema e TV, pertencentes à esfera jornalística e publicados na Folha de S.Paulo on-line. Para tanto, tomou-se como base os niveis interpessoais e representacionais da GDF, uma vez que elas preveem todos os aspectos pragmáticos e semânticos de uma unidade linguística.

A pesquisa ratifica a conceituação de encapsulamento como "sumarização de uma informação precedente, compartilhada pelos interlocutores" (KOCH, 2003, p. 94), mas entende que o fenômeno não se restringe ao sintagma nominal, nem sempre apresenta âncoras contextuais explícitas, como se pensava anteriormente. Conforme argumentamos, há termos gramaticais que, em determinadas circunstâncias, funcionam como anáforas encapsuladoras, assim como há encapsulamento cujo segmento a que se faz remissão não se encontra delimitado no texto. Acredita-se que tal mudança paradigmática nos confirme a não existência de invólucros predestinados a certas funções discursivas, pois, do contrário, significa impor limites aos processos cognitivos, pôr a função em serviço da forma, negar a preponderância da práxis sobre o uso linguístico.

Há toda uma mudança de perspectiva filosófica na passagem do modelo lógico-semântico para os de cunho pragmático - como a perspectiva sociocognitivo interacionista e discursivo-funcional de linguagem. Sentido, valor de verdade e referência a estado-de-coisa cedem lugar a comportamento, usuário, propósito de fala e situação de emprego. Afinal, como muito bem defendem Mondada e Dubois (2003), a questão não é localizar os objetos do mundo ou verificar a existência de entidades abstratas, mas entender como os sujeitos constroem versões públicas do mundo.

Quanto à função discursiva, confirma-se o consenso de que o encapsulamento é importante na condução e progressão de um texto, na medida em que traça uma orientação argumentativa para o texto, ao hipostatizar, transformar em tópicos discursivos predicações ou segmentos do discurso, e não referentes já disponiveis, lexicalizados. Crê-se que o reconhecimento, por parte do ouvinte/leitor, de qual segmento do discurso é encapsulado - se uma atitude proposicional, se um episódio, se uma propriedade etc. - possa ser uma ferramenta relevante à análise dos pontos de vista defendidos no texto. Pode-se, por exemplo, constatar que um discurso de outrem é encapsulado, pelo produtor do texto, como dúvida, crença ou atitude, muito embora o segmento em si não tenha essa conotação.

Por fim, cabe lembrar que, com a linguagem, faz-se muito mais do que nomear. Com um encapsulamento, por exemplo, não apenas se nomeia um segmento discursivo, pois, por trás dele, há a intenção de identificar algo a alguém, um querer dizer, um significar que demanda a leitura do contexto, dos propósitos da fala naquela determinada circunstância. Na verdade, não há objetos discriminados, individualizados em si, com propriedades essenciais, intrínsecas, independentemente de uma conceptualização cultural, linguística e semiótica, como defende a pragmática. 


\section{ANAPHORIC ENCAPSULATION: DEFINITION AND TYPOLOGY}

Abstract: According to Conte (2003, p. 178), the anaphoric encapsulation is "a cohesive term in which a noun phrase functions as a summarizing paraphrase of a previous portion of text", which scope is necessarily expressed in the co-text. However, in this paper, we support a redefinition of the phenomenon, since we recognize that there are encapsulations with pragmatic functions which scope is in the context - as well as others which are represented by a grammaticalized term. Finally, we propose a typological study of the anaphoric encapsulations through the pragmatic and semantic categories of Functional Discourse Grammar (HENGEVELD; MACKENZIE, 2008). Our corpora were extracted from 88 Movie Reviews from the newspaper Folha de S.Paulo, in the period of 2008 to 2010 .

Keywords: Encapsulation. Referentiation. Functional discourse grammar.

\section{REFERÊNCLAS}

APOTHÉLOZ, D.; REICHLER-BÉGUELIN, M. J. Papel e funcionamento da anáfora na dinâmica textual. In: CAVALCANTE, M.; RODRIGUES, B. (org.). Referenciação. São Paulo: Contexto, 2003. p. 53-84. (Clássicos da Linguística, v. 1). CONTE, M. E. Encapsulamento Anafórico. In: CAVALCANTE, M.; RODRIGUES, B. (org.). Referenciação. São Paulo: Contexto, 2003. p. 177-190. (Clássicos da Linguística. v. 1).

CUNHA, M.; SOUZA, M. Transitividade e seus contextos em uso. Rio de Janeiro: Lucerna, 2007.

DIK, S. C. The theory of functional grammar. Dordrecht: Foris Publication, 1989.

FRANCIS, G. Labeling discourse: an aspect of nominal-group lexical cohesion. In: COULTHARD, M. Advances in written text analysis. 9. ed. London: Routledge, 2003 [1994]. p. 83-101.

GARY-PRIEUR, M. N.; NOAILLY, M. Demonstrativos insólitos. In: CAVALCANTE, M.; RODRIGUES, B. (org.). Referenciação. São Paulo: Contexto, 2003. p. 229-249. (Clássicos da Linguística, v. 1).

HALLIDAY, M. A. K. An introduction to functional grammar. New York: Edward Arnold, 1985.

HENGEVELD, K. Cohesion in functional grammar. In: BUTLER, C. et al. (org.). Discourse and pragmatics in functional grammar (functional grammar series 18). Berlim: Mouton de Gruyter, 1997. p. 1-16.

HENGEVELD, K.; MACKENZIE, J. L. Functional discourse grammar. A typologically-based theory of language structure. Oxford: Oxford University Press, 2008.

KOCH, I. G. V. Desvendando os segredos do texto. São Paulo: Cortez, 2003.

KOCH, I. G. V. Referenciação e orientação argumentativa. In: KOCH, I.; MORATO, E. (org.). Referenciação e discurso. São Paulo: Contexto, 2005. p. 33-52.

LYONS, J. Semantics. Cambrigde: Cambridge University Press, 1977. 2 v. 
MONDADA, L.; DUBOIS, D. Construção dos objetos-de-discurso e categorização: uma abordagem dos processos de referenciação. In: CAVALCANTE, M.; RODRIGUES, B. (org.). Referenciação. Clássicos da Linguística. São Paulo: Contexto, 2003. v. 1, p. 17-52.

NEVES, M. H. M. Texto e gramática. São Paulo: Contexto, 2006.

SCHWARZ, M. Indirekte anaphern in texten. Tubingen: Niemeyer, 2000.

SEARLE, J. R. Les actes de langage. Paris: Hermann, 1972.

Recebido em 30 de abril de 2018.

Aprovado em 29 de agosto de 2018. 